\title{
BIBLIOGRAPHY
}

1. Travers, T. àB.-Concomitant Strabismus. Supplement to the Brit. Jl. of Ophthal., p. 44, January, 1936.

2. GRAEFE, A.-Quoted by CoRDS, R., in Kurzes Handbuch der Ophthal. (Schieck und Bruckner), Vol. III, p. 523, 1930.

3. Sherrington, C.-Brit. Jl. Psych., Vol. I, p. 26, 1904.

4. DuAne, A.-Ann. of Ophthal., October, 1903.

5. White, J Watson.-Amer. Jl. Ophthal. Vol. XIX, p. 653, 1936.

6. Helmholtz, H.-Physiological Optics. Translated from 3rd German Edition, Vol. III, p. 498, 1925. Optical Society of America.

7. Evans, J. N.-Amer. Jl. Ophthal., Vol. XII, p. 194, 1929.

8. MaYou, Miss S.-Brit. Jl. Ophthal.. Vol. XX, p. 360, 1936.

9. VAN KRIES, J.-Arch. f. Ophthal., Vol. XXIV, p. 117, 1878.

10. Worth, C.-Squint. 6th Edition, 1929. Baillière, Tindall \& Cox, London.

11. DuAne, A.-Trans. Ophthal. Soc. U.K.. Vol. XLV, p. 497, 1925.

12. Bielschowsky, A.-Arch.f. Ophthal., Vol. L, p. 406, 1900.

13. MUEGGE.-Arch. f. Ophthal., Vol. LXXIX, p. 1, 1911.

14. Tschermak, A.- Trans. German Ophthal. Soc., reported in Arch. $f$. Ophthal. New Series. Vol. IV, p. 597, 1930.

15. ChavasSe, B.-Trans. Ophthal. Soc. U.K., Vol. LV, p. 482, 1935.

16. HERING, E.-Quoted by CoRDS, R., in Kurzes Handbuch der Ophthal., Vol. III, p. 525, 1930.

17. Travers, T. àB.-As in 1, p. 22.

18. LYLE, K., and JACKSON, S.-Practical Orthoptics in the Treatment of Squint, p. 53, 1937. H. K. Lewis, London.

19. Pugr, M. A.-Squint Training, p. 21, 1936. Oxford University Press, London.

\section{A NEW TECHNIQUE FOR THE APPLICATION OF RADON SEEDS TO THE SCLERA IN THE TREATMENT OF GLIOMA RETINAE}

\author{
BY \\ H. B. Stallard \\ LONDON
}

THE value of radiotherapy in the treatment of glioma retinae has become established. A number of cases have been reported in which this neoplasm has proved to be very radiosensitive and when of a moderate size it has disappeared and there have been no recurrences in periods up to 9 years after irradiation; some useful vision has been retained and the child's life saved.

Foster Moore at St. Bartholomew's Hospital used at first interstitial irradiation. He incised the sclera over the centre of the neoplasm using an angular knife with two cutting edges and the exact width of this instrument equalled the diameter of a radon seed. One side of the blade was painted with sterile gentian violet solution to mark the site of the scleral incision after the knife had been withdrawn. The point of the knife was passed through the sclera and choroid and entered the base of the neoplasm. On 
its withdrawal a radon seed in a special holder was introduced point first into the incision and secured in position by passing the black silk suture, which emerged from its other extremity, through a sterile circular rubber disc placed over the adjacent sclera. This procedure was in time abandoned in favour of suturing the radon seed or seeds to the sclera at the desired site. For this purpose a shallow groove is fashioned in the platinum envelope half-way along the length of the seed and in this a 000 black silk suture is
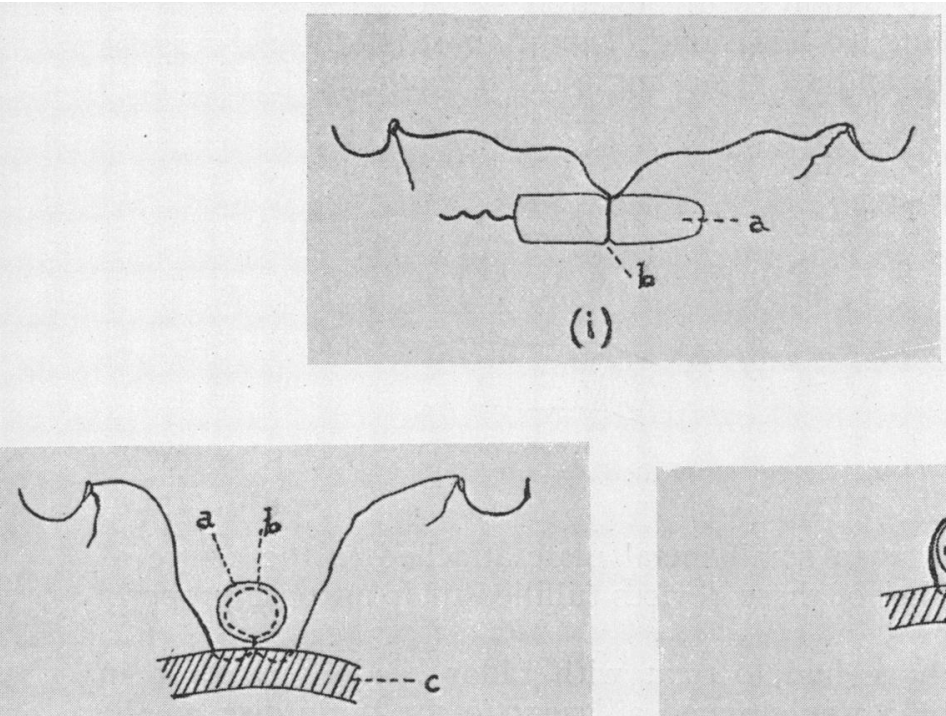

(ii)

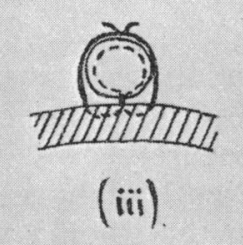

a. Radon seed.
b. Groove.
c. Sclera.

FIG. 1 .

tied and to the free ends of this suture very small half-circle arterial needles are threaded.

The method which I have used for fixing the radon seed to the sclera is shown in Fig. 1.

This technique may be readily effected as far back on the sclera as the temporal extremity of the inferior oblique muscle insertion and by using a double pronged retractor inserted into the superficial layers of the sclera and an Arruga's retractor the sclera adjacent to the optic nerve can be reached when the external rectus muscle is divided and an external canthotomy has been performed. In the posterior sclera around the optic nerve it is difficult to 
manoeuvre even the finest needle holder, the needle and the radon seed, with the degree of precision and accuracy so desirable in these cases.

For this purpose Foster Moore tried an ingenious device in the form of a narrow spring metal band, encircling $\frac{3}{4}$ of the circumference of the radon seed, with 2 fine teeth set obliquely at the extremities of the band. The band was compressed by forceps and an attempt made by the spring action of the band to engage its teeth in the superficial layers of the sclera. (See Fig. 2.)

I tried also to obtain secure fixation in the sclera by fixing 2 fine needle points $0.6 \mathrm{~mm}$. long, $2 \mathrm{~mm}$. apart, slightly diverging from each other and set at an angle of $60^{\circ}$ with the long axis of

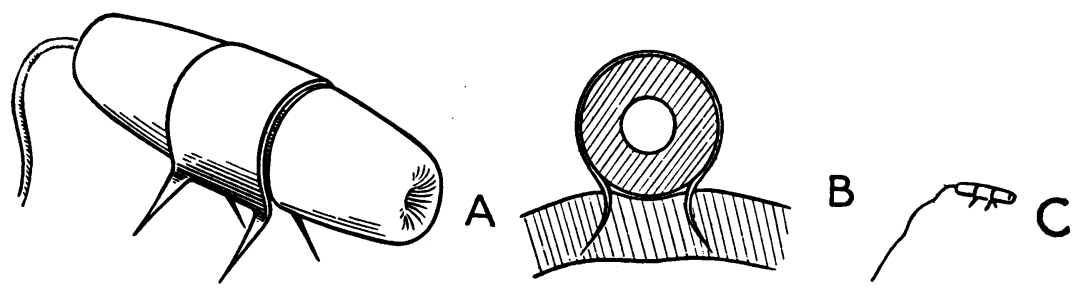

FIG. 2.

the radon seed, in a small metal plate attached to the centre of the seed. Neither of these devices fulfilled their purpose properly and securely.

Recently I have had to treat with radon seeds 2 children in whom the glioma was situated adjacent to the optic disc on the temporal side. In both these cases surgical access was gained as far as the dural sheath without apparent damage to any important structures.

A strip of heated Stent dental wax $4 \mathrm{~mm}$. wide and $2 \mathrm{~mm}$. thick was taken and moulded to the sclera over the site of the growth and brought forwards in the meridian of the neoplasm to a point about 3 or $4 \mathrm{~mm}$. in front of the equator. The posterior extremity of this strip extended to within $1 \mathrm{~mm}$. of the dural sheath of the optic nerve. The position of the lateral margins and anterior extremity of the Stent strip were then marked by charring the superficial layers of the sclera with a few touches from the point of a fine heated probe. The strip was then removed and with small eyeless cataract needles, used for corneo-scleral stitching, 2 sutures were passed through the superficial layers of the sclera about $2 \mathrm{~mm}$. in front of and $3 \mathrm{~mm}$. behind the equator as shown in Fig. 3.

The ends of these sutures were left loose. The posterior extremity of the Stent was reheated in hot sterile water and a radon seed 


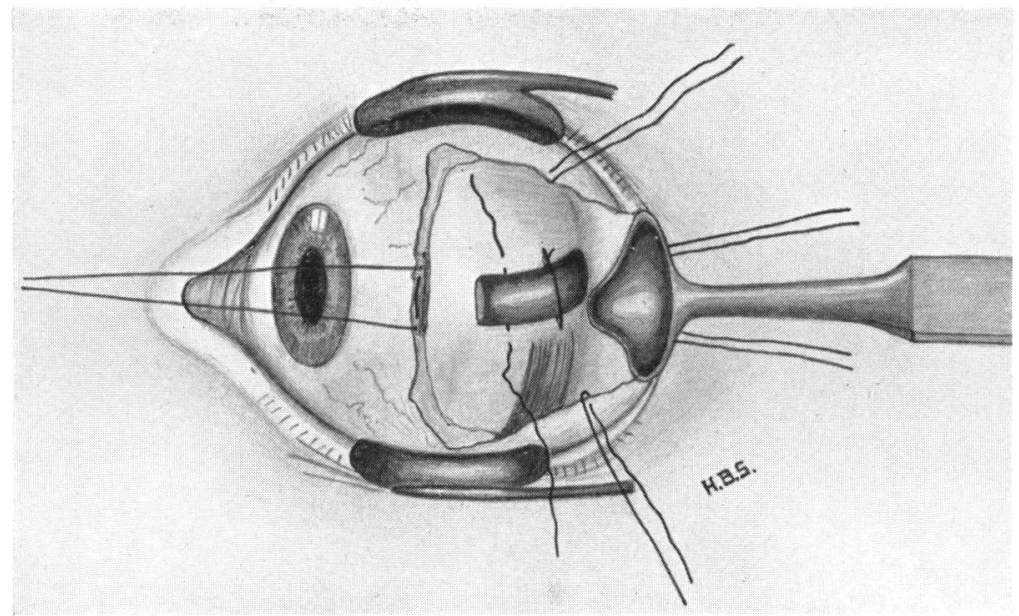

FIG 3.

Left eye. The external rectus muscle has been divided and the eye rotated to the nasal side by a suture passed through the tendon of the muscle. The insertion of the inferior oblique muscle and the posterior part of the sclera are exposed. The strip of Stent dental wax is shown in position above the insertion of the inferior oblique muscle.
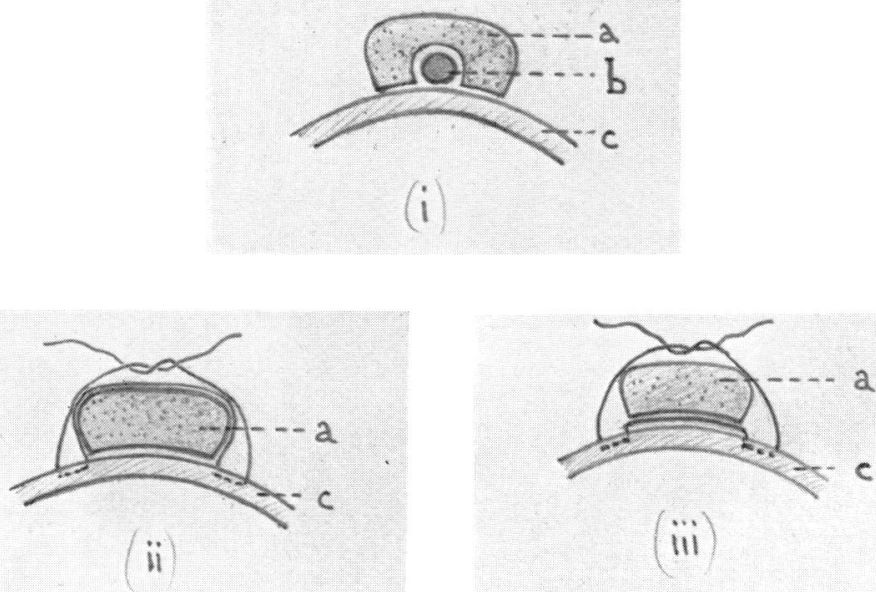

FIG. 4.

a. Strip of Stent dental wax moulded to sclera.

b. Radon seed embedded in Stent.

c. Sclera.

(i) Is a cross section through the end of the strip of Stent holding the radon seed.

(ii) and (iii) Show alternative methods of suturing the Stent strip to the sclera in front of and behind the equator (see text). 
pressed into its concave or anterior surface, the seed being so placed that with the Stent strip secured in position it lay over the neoplasm. The strip with the radon seed was then placed on the sclera and final adjustments were effected by heating a broad flat spatula and pressing it against the strip at the requisite points. The 2 sutures were then brought over the Stent strip which was slightly heated and softened where the sutures crossed it so that they became embedded for about $0.5 \mathrm{~mm}$. before being tied. The

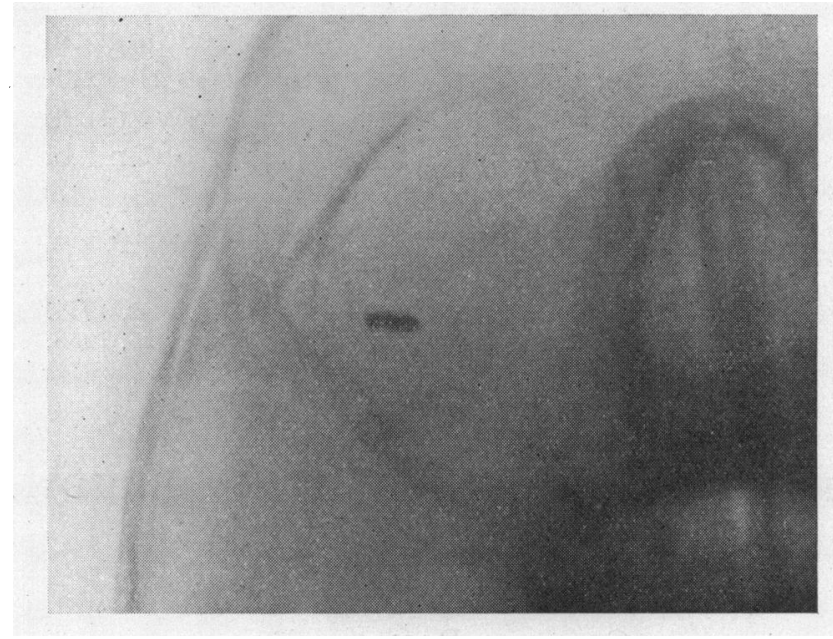

FIG 5 .

Radiograph showing radon seed in position.

edges of the Stent strip and any rough places were smoothed and rounded off by applications of a heated flat spatula (Fig. 4).

The divided edges of Tenon's capsule, the external rectus muscle and the conjunctiva were brought together and sutured. The radon seed remained firmly in position, a fact confirmed by a radiograph taken on the 3rd or 4th day after operation (see Fig. 5) and at the removal of the radon seed on the 8th day after its insertion.

In the two cases mentioned above irradiation of the growth has up to date proved to be effective. The presence of the Stent strip gave rise to no increased irritation and there was no infection or sepsis in either of the cases.

To date there has been no ophthalmoscopic evidence of any damage to the optic nerve head nor to the intra-ocular media.

This method of retaining a radon seed in apposition to the posterior extremity of the globe is technically simple, is effective and without complications. The posterior extremity of the Stent strip could be enlarged or divided into two or more branches for 
the accommodation of additional radon seeds. For instance, in a case in which there was a large mass of glioma extending above and below the macula the posterior extremity of the Stent strip could be bifurcated, each division carrying a radon seed, one passing above the insertion of the inferior oblique muscle and the other below and between the muscle and the globe.

\title{
Summary
}

This paper describes a method of applying radon seeds to the posterior part of the sclera by means of embedding the seed or seeds in a strip of Stent dental wax moulded to the sclera at the desired site. The Stent strip is secured in place by sutures traversing the superficial layers of the sclera in front of and behind the equator.

\section{REPERENCES}

Foster Moore, R.-Trans. Ophthal. Soc. U.K., Vol. LV, p. 3, 1935. Stallard, H. B.-Brit. Med. Jl., Vol. II, p. 962, November 14, 1936.

\section{CATARACT ASSOCIATED WITH AN HEREDITARY RETINAL LESION IN RATS}

BY

\author{
Margherita Cotonio Bourne, Dorothy Adams \\ CAMPBEll and MAgNus PyKe
}

\section{from}

THE DEPARTMENT OF PHYSIOLOGY AND BIOCHEMISTRY, UNIVERSITY COLLEGE, LONDON, AND THE MIDLAND AND BIRMINGHAM EYE HOSPITAL

Aвоut three years ago our attention was called to the occurrence of cataract in a colony of rats kept by a research laboratory.* It had been observed that from time to time mature bilateral cataract appeared in a healthy animal, which had been kept for breeding purposes and had never been subjected to any experimental procedure or dietary deficiency. The cataract was not the result of an injury; the animals grew well, reproduced reasonably well, and, apart from the cataract, showed no pathological symptoms. Since there was no obvious explanation for the appearance of this cataract, we concluded that an hereditary factor might be involved.

We received in the first instance a cataractous female rat with

* We are greatly indebted to Messrs. Vitamins, Ltd., for drawing our attention to this cataract and for presenting us with affected animals. 